\title{
On the Prevention and Fight Against Ageing Population Fraud Crime Question Research
}

\author{
Jing Zhang, Xin-qian Gu \\ Department of Ideological and Political education, Shenyang Jianzhu University, \\ Liaoning Province, China
}

\begin{abstract}
In the period of social transition of China, at the same time, china is running into aging countries. Two aspects of the situation occur simultaneously and interaction, coupled with the elderly special body status, mental status, for the elderly of the implementation of fraud crime is staged continuously. Involving property, medicine and emotion. This paper puts forward the prevention primarily, supplemented by a severe blow. The complexity problem dictates the need of government departments to jointly fight and the attention of the whole society; to establish the group for the ages, increase the propaganda education, strengthen the consciousness of fraud prevention; countries provide the strongly legal for protection; The families should construction and channel the psychology of the elderly; to protect the rights and interests of the elderly by forming the organization system ,that is to set up specialized agencies.
\end{abstract}

Keywords — elderly, fraud, prevent, fight

\section{关于预防与打击针对老龄人口 欺诈犯罪活动的问题研究}

\author{
张晶＼cjkstart顾心倩 \\ 沈阳建筑大学思政部，沈阳市，辽宁省，中国
}

摘 要 处于社会转型期的中国, 同时也在跑步进入老龄化国家。两个方面的情况同时发生并相互作用, 再加之老年人特殊的身 体、心理状况，针对老年人实施的欺诈犯罪案件不断上演。其中涉及财物、医药和情感三类骗术最易使老年人上当。本文提出预防为 主, 辅以严厉的打击。问题的复杂性决定了需要政府各部门联合打击及全社会关注; 成立老年教育团体, 加大教育宣传、增强防骗意 识；国家提供针对性强的法律保障；家人对老年人的心理建设及疏导；以组织建制形式即成立专门机构保护老年人权益。

关键词 老年人, 欺计, 预防, 打击

1. 引言

当代中国正处于社会转型期, 而同时中国也在跑步进 入老龄化国家, 这样的时代背景导致下面两个方面的情况 同时发生并相互影响。一方面, 社会转型期不容忽视的存 在着贫富差距、社会保障滞后、贪污腐败等问题, 这些都 极易导致仇富、仇腐心理的出现和平均主义心态的复发, 从而增加了社会矛盾, 导致犯罪的多发; 另一方面, 我国 2 亿多 60 岁及以上老年人口的存在, 其中我们辽宁省老年 人口比重在全国各省、自治区中遥遥领先。因老年人与社
会不同程度的脱节, 反应较为迟钝、容易轻信别人、封建 迷信思想重、或贪心或滥发善心、身体状况等弱点的存在, 以老年人为欺计犯罪对象的诈骗犯罪事件不断地上演。

\section{2. 针对老龄人口欺诈犯罪活动多发的原因}

\section{1 时代背景}

我国经历三十多年的改革开放, 国民经济快速的发展, 既带来生产力和人民生活水平的大幅提高, 也带来了一系 列的负效应。我国社会目前正处于转型期, 诱发刑事犯罪 
的各种消极因素大量存在。加之负效应的积累作用, 使得 贫富差距逐渐扩大, 贪污腐败严重, 一些国民相应的社会 保障制度滞后。三十几年形成的负效应积累是需要一个过 程来减小、消解的, 但很多人意识不到这需要时间段来保 证, 直接后果就是一些人的仇富、仇腐心理加重, 一些人 的道德水准下降, 不劳而获的心理滋生, 更严重的就发展 为欺计犯罪。同时处于科技高速发展的当今时代, 网络, 各种新科技层出不穷, 而人们对其认知水平又是参差不齐, 各种欺诈犯罪应运而生。如电信诈骗、网络诈骗等, 犯罪 分子付出很低的成本就可收获高回报, 并且手法很简单, 很容易传播、仿效, 并且法律对其打击力度低, 银行、电 信行业又存在许多监管漏洞, 而如大量的私人信息的泄露, 这也是社会管理层面的一种漏洞。在这种社会发展的大背 景下, 欺诈案件在今后一段时间内仍然会处于一种高发的 状态。

\section{2 老年人自身身体、心理因素}

以老年人为欺诈犯罪对象的诈骗犯罪事件不断地上 演, 这与老年人自身的特点是分不开的。60 及以上的老年 人已逐渐从社会主要角色中退出, 而同时自己身体机能也 在逐渐衰退, 在脑力上老年人的判断力、辨别能力以及反 应能力都会有所衰退, 这种整体识别能力的下降是人的自 然生理规律。但是很多不法分子就是针对老年人的这个特 点进行欺计犯罪。

同时, 随着社会的高度发展, 人的工作生活压力增长, 很多家庭的子女与老人都不在一个地点生活, 就造成了很 多空巢老人的出现。心理学认为, 心理防御如果失败了, 人类就会产生一种习得性无助, 甚至发生抑郁。[1]这些空 巢老人因孤独产生的抑郁和渴望与人交流、容易轻信他人。 而随着国民经济的快速发展，人民生活水平的不断改善， 老年人的消费也在逐步提高。但由于年龄、信息不畅等因 素, 老年人在获取消费知识、维护自身合法权益等方面都 处在弱势地位。迎合老年人对日用品、对饮食、对穿着、 对医疗的更高追求, 对精神享受的更高层次的需要, 很多 骗子就在这些方面屡试不爽, 老年人成了被欺计的重灾区。

\section{3. 针对老龄人口欺诈犯罪活动具休形式}

在诸多针对老年人实施的欺计犯罪案件中, 涉及财物、 医药和情感三类骗术最易使老年人上当, 这是与老年人自 身体弱多病、容易轻信别人、信心或滥发善心这些特点密 切相关的。

炒作概念误导老年人, 用免费体验、体检、使用等蒙 蔽老年人, 雇用“托儿”来诱骗老年人上当, 还有各种中奖
陷阱来诱惑老年人。近年来随着信息化高速发展, 网络渗 透到我们生活的每一个角落, 针对老年人实施的欺计犯罪 案件的手法除之前的“婚托、电视购物、免费体验、街头骗 术”等形式之外, 电信诈骗、网络诈骗, 甚至于更新的电信 与网络结合诈骗手段层出不穷。电信诈骗和网络因其成本 低, 方法灵活, 且目前的法律及电信、银行等部门对其监 管存在漏洞, 正成为目前欺诈老年人的主要的犯罪形式。

主观幸福感 (SubjectiveWell-Being, SWB) 是衡量老年 人生活质量和身心健康的核心指标之一。主观幸福感的基 本特点之一是主观性, 以评价者内定的标准而非他人标准 来评估。 ${ }^{[2]}$ 本文强调要以预防为主, 不发生、少发生针对 老龄人口欺计犯罪活动, 对老年人的伤害降到最低。最大 程度上实现老年人的主观幸福感。在预防的过程中, 老人 家庭中亲人的作用至关重要, 从心理上解决老人的情感、 认知等问题, 都离不开亲人的努力和陪伴。在此基础上, 再加以全社会共同合作对各类欺诈犯罪活动给以打击, 努 力从根源上消灭这类犯罪活动, 为我国平稳进入老龄化社 会做出积极的贡献。

\section{4. 关于预防与打击针对老龄人口欺诈犯罪活动的对 策与建议}

\section{1 问题的复杂性决定了需要政府各部门联合打击及全社 会关注}

上述欺诈手段的复杂性决定了只有所有的相关部门联 合执法, 行动起来。再加上全社会对这个问题的重视, 才 能预防与打击针对老龄人口的欺计犯罪活动。例如, 电信、 银行、工商、公安、法院、民政、广播影视、社区、老龄 委、消协等部门联手合作, 齐抓共管, 严厉打击虚假宣传 和侵犯老年消费者权益的违法行为, 让欺计老年人的黑手 无处可伸。各级政府要把预防与打击针对老龄人口欺诈犯 罪活动, 保障老年人权益工作作为一项重要任务, 纳入议 事日程, 采取更加积极有效的措施, 全面提升工作的整体 水平。

\section{2 成立老年教育团体, 加大教育宣传、增加防骗意识}

老人们大多没有通过正规渠道接受过维权方面的教育 和警示, 可成立老年教育团体, 就为老年人服务, 为老年 人提供各种帮助为目的。当老年人在退休后的自我角色定 位上出现问题时, 可以给他们提供咨询及建议; 老年人也 可通过团体的课程, 学习新技巧, 了解社会的最新信息, 新技术的使用等, 保持健康有活力的心态。不会因心理问 题、因无聊寂寞而上当受骗。老年人应多了解社会上不良 现象, 拓宽自己的视野、更新日常知识等, 学习一些必需 
的理财常识, 提高自己的防骗能力。

\section{3 国家提供针对性强的法律保障}

我国现在已初步形成一个全方位、多层次对老年人权 益进行保护的法律体系。这一体系不仅确认了老年人享有 与其他公民同等的权益, 而且还给老年人权益以特殊保护。 但在具体实施的过程中, 因社会背景的变化等原因而表现 出针对性不强的缺点。因此迫切需要针对最新的对于老年 人的欺计犯罪活动特点, 建立出台新的针对性强的法律进 行保障, 比如个人的泄露、电信诈骗、银行批量开户等等。 同时应该注意到老年人虽然是具有完全民事行为能力, 但 由于他们的生理状况的特殊性, 他们对于事物的判断能力 会和社会的正常人群有所不同。

\section{4 家人对老年人的心理建设及疏导}

在我国, 子女对于老年人的晚年生活具有重要意义。 尤其在我国老龄化大大超前于经济发展, 未富先老, 超出 了社会经济的承受能力的条件下。以家庭为单位, 为老年 人老年生活考虑周全, 作出规划是非常必要的。有研究表 明, 家庭的支持是美国老年人的健康最期望来源, 而在中 国则为邻里与朋友的支持。 ${ }^{[3]}$ 这个研究为我们敲响了警钟, 父母和子女的感情交流不容忽视。在关心和改善老年人物 质生活条件的同时, 应注意在人际关系、情感和精神方面
为老年人创造宽松、和谐、温馨的社会、精神和心理环境, 增强其生活满意度和幸福感; 子女应“常回家看看”,多给老 人精神慰藉,并帮助他们提高辨识骗局的能力。帮助老年人 避免因心理空虚、情感寂寞陷入各种欺计犯罪。

\section{5 以组织建制形式即成立专门机构保护老年人权益}

因针对老年人欺诈犯罪活动的复杂性，保护老年人合 法权益的重要性和严重性, 除了上面提到的立法保护、心 理疏导等办法之外, 迫切需要我国以组织建制形式来保障 老年人不受欺计犯罪的伤害。设立专门机构保护老年人合 法权益, 防止各部门之间的推委、不作为行为的发生, 有 这样的一个专门机构负责进行执行和监管, 可以更有利于 打击针对各种欺诈犯罪活动, 减少其对老年人的伤害。

\section{参考文献(References)}

[1] Dennis Coon John O. Mitterer. Gateways to Mind and Behavior. Beijing: China Light Industry Press. 2008pp. 582

[2] DienerE, Sapyta JS, Suh E1Subjective well-being. Psychol Inquiry, no. 9. pp. 331. 1998.

[3] DENG Rong. Three Sources of Informal Support and Psychological Well-Being. Journal of Guizhou Normal University (Social Science), no. 6. pp. 133-136. 2010. 